\title{
Providing Effective Mental Health Support to Japanese University Students: The Use of a Typological Approach at a University Mental Health Support Center
}

\author{
Kazunori Kakei ${ }^{1}$, Yuri Uesaka ${ }^{*}, 2$ and Emmanuel Manalo ${ }^{3}$ \\ ${ }^{I}$ Showa University, Japan \\ ${ }^{2}$ Tokyo Institute of Technology, Japan \\ ${ }^{3}$ The University of Auckland, New Zealand
}

\begin{abstract}
In line with the many unique facets of the Japanese culture and social environment, there are some unique mental health problems among the Japanese. One example is "student apathy", a mental health condition that is not commonly discussed outside of Japan, particularly in Western countries like the US. This paper discusses how such problems, when experienced by students, are dealt with by the university health support system in Japan. To tangibly illustrate the strategies that are employed, specific aspects of the support provisions of a mental health center in one Japanese university are used as examples. In this center, students with mental health problems are categorized into three types. The first category comprises students who have primary complaints that are concrete in nature, and have remained comparatively healthy in their mental states. For these students, a solution-focused approach is used. The second category is of students who have a more vague primary complaint, and who are not as mentally healthy as those in the first category, but are not yet at the level that requires clinical care. Students suffering from student apathy are included in this group. For these students, a combination of the psychoanalytic approach and the solution-focused approach is used. The third category is of students who have the most serious mental health problems: for many, the severity of their problem is such that they cannot visit the health support center by themselves. For students who are placed in this category, a support network approach is used, as well as medical support from a doctor when required. By categorizing and clarifying appropriate strategies, effective support can be put into practice with the use of the limited human resources available within the university's mental support center.
\end{abstract}

Keywords: University students' mental health, student apathy, Japanese students, identity crisis, cultural uniqueness, intercultural understanding.

\section{INTRODUCTION}

This paper will discuss mental health support provided for students in Japanese universities. "Student apathy" is one of the most serious and prevalent problems among university students in Japan [1-5]. The term was first used by Walters [6] in order to explain the condition of apathetic university students in the US. These students do not want to do anything, and the manifestations of their condition become a concern to their educational institutions because, among other things, they contribute to a decline in academic standards. Although student apathy and simple idleness appear similar, they are quite different: it is almost impossible, for example, for students suffering from student apathy to get over the problem on their own. Appropriate mental health support by counselors is usually necessary for students to overcome the problem [4]. Student apathy is also different from depression in that those suffering from apathy tend to attribute their problems more to external reasons than to internal ones [7].

*Address correspondence to this author at the Department of Human System Science, Graduate School of Decision Science and Technology, Tokyo Institute of Technology, 2-12-1-W9-18, Ookayama, Meguro-ku, Tokyo 158552, Japan; Tel/Fax: +81-3-5734-3240;

E-mails:y.uesaka@nm.hum.titech.ac.jp,yuri.uesaka@08.alumni.u-tokyo.ac.jp
Shimoyama [4] pointed out that student apathy has rarely been debated except in Japan. For example, only a few studies on student apathy have been published in Western countries subsequent to the publication of Walters' chapter. In fact, even a comprehensive textbook on university student mental health support written by Gason and Gauley [8] does not mention student apathy at all. In contrast, in Japan, studies on student apathy began in the 1970s, about a decade after the Walters' chapter and a number of experimental studies have been published particularly since the late 1980s [9-15]. Student apathy is also still under debate in Japan. For example, Manalo, Koyasu, Hashimoto and Miyauchi [1] found that Japanese students studying in Japanese universities have higher levels of amotivation (i.e., perceiving no contingencies between outcomes and one's own actions) compared to their counterparts studying overseas, and they attributed this to the domestic-based students possessing more negative views about themselves and the future. Mouri and Sagami [16] also recently argued that students who have unhealthy relationships with their parents often become apathetic.

As will be discussed later, the unique social situation in Japan may well promote the development of a unique type of student apathy, and this in turn has probably promoted student apathy studies in Japan. Japanese university students 
are often apathetic not only about their study but also about getting jobs. Furthermore, some students are apathetic about their future and avoid making decisions about their future career. This type of student apathy is unique to Japan and rarely reported in Western countries. Shimoyama [4] and other researchers [17-19] have argued that university students who avoid making decisions about their future career are considered exceptional in other countries. According to Shimoyama [4], in the US and European countries, career choice is regarded as one of the most important decisions in life, and high school students choose universities in consideration of their future career aspirations. However in Japan, high school students do not choose universities according to their future career aspirations. Shimoyama [3, 20, 21] pointed out that high school students in Japan usually select universities according to their score in high school or their parents' opinions without considering their own reasons. As a consequence of this, Japanese students often regard entry to a university as the final goal, and cannot decide their future careers even after they enter university.

Student apathy is considered a serious problem among Japanese university students and numerous research papers on student apathy have been published in Japan - although, regrettably, most of the papers have only been published in Japanese. However, in response to the issues and problems that have been identified, a variety of student mental health support systems are being developed in Japan according to the unique Japanese social situation and the unique characteristics of Japanese students. These systems are being developed by university staff from a variety of fields of expertise in collaboration with counselors, and they typically use the following cyclic steps: (1) Evaluating existing systems and services and studying students' needs, (2) Planning and developing new systems and services, and (3) Adopting the new systems and services [22]. These systems, which meet Japanese student needs, probably contain some key features that are unique internationally.

In this paper, several approaches used by a student mental health counseling office will be described. The aim is to introduce some of the context-driven features of the mental health support provided by this particular counseling office and, in doing so, provide information for researchers in Japan and in other countries to facilitate possible comparisons, and inter-institutional and intercultural learning. The authors hope that such comparisons and learning could in turn contribute to the development of more effective support systems for students.

This paper is the product of collaboration between student support practitioners and academics: the first author is a university mental health counselor and the cases and support systems described in this paper are drawn from his practice; the second and third authors are academics who both work in the area of developing and providing more effective systems for supporting student learning, and were therefore able to provide the necessary theoretical and research contexts to the support systems described in this paper. Collaborations of this kind are important in bringing to the attention of a wider audience innovative practices that often remain unreported despite their potential to contribute to the development of knowledge and more effective systems for dealing with pressing issues in education, as well as in other disciplines.

\section{THE UNIQUE SOCIAL SITUATION IN JAPAN AND THE MENTAL HEALTH PROBLEMS AMONG JAPANESE UNIVERSITY STUDENTS}

As mentioned earlier, Japan's unique social situation probably causes unique mental health problems, including student apathy. Japanese high school students usually determine the university they will enter in a different way from students in other countries. As a likely result of this process, they suffer from unique mental health problems like student apathy when they get to university. Therefore, this section will describe how high school students in Japan choose universities, as well as discuss the mental health problems that appear to stem from this.

Shimoyama [21] undertook a 5-year longitudinal study of the university choices made by high school students in Japan and examined how their assessment scores in high school influenced their choices. His findings clearly showed that most of the high school students decided on their universities according to their assessment scores. They selected a highranking university that they had a chance of successfully entering and chose a faculty and major according to their score. In determining a university, the majority did not consider what they wanted to be in the future. Shimoyama [21] also interviewed high school teachers. He reported that high school teachers also provided advice on university choice to students, referring to the students' assessment scores when they did so. The teachers did not deny such an approach to decision making. In Japan, students who graduate from high ranked universities can usually find work with major companies and get a good salary. This situation probably causes this approach that students use in deciding the university they will aim to enter.

Consequently, a number of students enter universities without even considering what they want to study. This sometimes causes mental health problems among university students. A significant proportion of high school students study just so that they can enter a high ranked university. Many students who fail the entrance exam experience serious psychological distress. But students who pass the exam need to confront a new question: "What do I want to do at university?" In fact, according to Sonaka and Aoki [23], a notable proportion of Japanese students change their faculties and majors during their time at university because they were initially unprepared to confront this question.

This problem also causes a crisis of identity among university students in Japan. This crisis can probably be best understood in terms of Marcia's concept of "identity foreclosure" [24] whereby an individual commits to a set of goals, values, and/or beliefs without first exploring and really understanding what those commitments really mean and/or entail for him or herself. The individual becomes reliant on the "security blanket" that comprises the circumstances and individuals that have helped put those commitments in place: in the case of Japanese students, those would be their parents, teachers, schools and their associated expectations. However, when the security blanket is removed, "foreclosed" individuals tend to go into crisis, not knowing what to do in the absence of those 
circumstances and individuals they have been accustomed to $[25,26]$. This appears to be what happens to many Japanese students when they go to university and are confronted with important decisions they have to make on their own.

In other countries, one important way in which students develop their identity is through the process of determining their future careers and universities. However, because of the different circumstances that Japanese students face, their corresponding identity development has to take an alternative or modified route. During their time at university, Japanese students confront a variety of new problems in their student life, in part-time jobs they undertake, and in group activities they participate, and have to make decisions by themselves. Through the process of dealing with these problems, they reflect on themselves and gradually develop their identity: Marcia referred to this process as "exploration", whereby an individual engages in problemsolving behavior in order to find out more about him or herself and his or her environment in order to make important life decisions [27-29]. However, in this process, some students cannot effectively reflect on important issues about themselves and fail to develop their identity. Such students often need the help of counselors in their universities.

Identity crisis is one of the key issues that need to be dealt with in the provision of student mental health support in Japanese universities. The degree of the crisis varies between students. Some students can get over their identity problems following a brief counseling session. But others, who suffer heavily from identity problems, cannot even come to see counselors. In such cases, other people around them often have to seek the mental health support on their behalf. In most Japanese universities, only a few counselors are employed to provide services for significant numbers of student clients. Therefore it is necessary to establish efficiency in the mental health support systems that are provided for students. Such systems need to provide support according to the degree of severity of the mental health problems being experienced by the students.

\section{UNIQUE APPROACHES USED IN A JAPANESE UNIVERSITY COUNSELING OFFICE}

In Japanese universities, counselors are limited in number. Therefore inadequate counseling (not enough time) is a common problem faced in most universities. For example, in the first author's counseling office, only two counselors work three hours per week for a total of 700 students studying on that campus, which is typical in Japan. As student counseling is usually provided on an individual basis, counselors do not have enough time to devote to each client.

Student clients in Japanese universities are usually from the same generation and they suffer from similar types of mental health problems. Therefore it is possible to place students in a number of categories according to their mental health problems - in other words to use a "typological approach" in order to formulate an effective policy and prepare in advance the counseling approaches to use. The term "typological" here is not used in the same strict manner that it is used in scientific disciplines like biology. Here the term is used in a more flexible and pragmatic manner - to describe an approach that is essentially aimed at facilitating greater efficiency in the counseling process and making counselors' workload more manageable.

In the first author's counseling office, clients are categorized into three groups. Clients who are reasonably healthy in their mental state and have high adaptive ability are classified into the first group. They usually come to see the counselor with some understanding of the causes of their mental health problems. They can explain the issues relating to their problem clearly and in sufficient detail. They can also usually deal with their problems by themselves.

Clients who are moderately healthy in their mental state and have moderate adaptive ability are classified into the second group. They usually come with several problems that they cannot explain with sufficient clarity. Their mental health problems are often fundamentally caused by an identity crisis. Students suffering from apathy are normally classified into this group.

Clients who are likely suffering from psychiatric disorders are classified into the third group. They are rarely able to deal with their problems by themselves. Therefore, people around them usually come to see the counselors in order to ask and arrange for the provision of mental health support for these clients.

In the first author's counseling office, the approaches used to support the student clients are in accordance with their group assignment. Each of the approaches is described below. It is important to note here, however, that the counselors constantly monitor the student clients' mental health condition and progress. In line with this monitoring, there is adequate flexibility built in the group assignment process so that, if or when a client's mental health condition significantly changes or the initial assignment proves inappropriate, the client is re-assigned to another group.

\section{The Approach Used with Clients in the First Group}

Students in the first group experience problems that are often related to dealing with personal relationships, such as being able to get along with their room mates and establishing effective working relationships in group activities. A solution-focused approach is used with this group, an approach which is also referred to as "solution focused brief therapy (SFBT)" [30]. This approach was originally developed for drug, alcohol addiction, and child abuse counseling and was found to be dramatically effective in addressing those problems [31]. Although currently this approach is not prevalent in university student mental health counseling, findings from experiments by Harada [32] showed that it is effective when used in this context. The solution-focused approach is also being introduced into the practice of counseling school children [33]. In the first author's counseling office, this approach is actively used in providing counseling for the students who are relatively healthy in their mental states and can understand the causes of their problems.

In his paper, Chiba [34] compared the solution-focused approach with behavior therapy (as a more traditional counseling approach) and concluded that the former is more positive and future oriented than the latter. The aim of many traditional approaches to counseling is to clarify the negative 
factors causing the problem. In contrast, in the solutionfocused approach, the counselor leads the client to envision a preferable future and undertakes the counseling process using this positive future image $[34,35]$. The counselor asks positive questions such as "How would you like things to be in the future?" Special questioning techniques are used, such as the miracle question technique in which the counselor asks questions like "What would you be doing if a miracle occurs and all of your problems are solved?" Such questions help the client to imagine what he or she would prefer in his or her future. The counselor then helps the client to set shortterm achievable goals toward the preferable future. In the solution focused-approach, the client rather than the counselor sets the concrete goals. This is another point of difference between the solution-focused approach and more traditional counseling approaches [35].

\section{The Approach Used with Clients in the Second Group}

Some students suffer from more complex mental health problems. The clients in the second group usually cannot explain their mental health problems clearly and do not understand what causes the problems. Their complaints include comments like "I don't want to do anything", "I want to quit university", "I do not want to go to my classes", and "I do not understand why I should go to university". Their complaints are usually vague in terms of explaining their actual problem. Some students suffer from what appears to be a combination of several problems. Although drug therapy is not necessary, students in this category are deemed less healthy in their mental states than the clients in the first group. Their mental health problems also cause more severe difficulties in their life. Some students cannot go to school, eat, or sleep as a consequence of their problems.

Counselors usually ask clients in the second group questions about their past and family environment in order to clarify the main and fundamental factors causing their problems. In most cases, the fundamental factors turn out to be the source of an identity crisis, as well as being the direct cause of the mental health problems the students manifest. Again, in most cases, the clients do not notice the existence and/or relevance of these fundamental factors. This approach of seeking unconscious or subconscious root causes of present problems in the past was originally developed in psychoanalysis.

While only the solution-focused approach is usually applied to clients in the first group, both the psychoanalytic and the solution-focused approaches are used with those in the second group. This is because the solution-focused approach is only effective with clients who understand what causes their mental health problems and are capable of dealing with the problems themselves [34]. Therefore, for clients in the second group, the psychoanalytic approach is first used. Once the fundamental factors causing the mental health problems have been clarified, the solution-focused approach is applied in conjunction with the psychoanalytic approach.

\section{The Approach Used with Clients in the Third Group}

The clients in the third group are usually more seriously unwell in their mental states. As noted earlier, instead of the clients themselves, the people around these clients usually come to see the counselors to seek the necessary forms of support. These other people, who are usually close to the client in various ways (e.g., his or her tutors, room mates, parents) describe the client's condition in terms like: "He looks so mentally ill, so please come to see him", and "We do not know how to cope with her problem because she always cries when we try to talk with her". For this group of clients, the counselors sometimes need to contact other medical institutions for assistance. According to Fukuda [36], drug therapy at a hospital is necessary when the client suffers from a combination of mental depression, fears, and hallucination. Furthermore, the counselors usually create a support network for the clients in this group. Shimoyama [37] pointed out that, for students suffering more serious forms of mental health problems like those in this third group, it is important to create a support network between counselors, tutors, and the clients' parents. The use of a support network in providing mental health care was introduced into psychiatric practice relatively recently following a paper by Engel [38].

The mental health support provided for clients in the third group is non-imposing and provides sufficient latitude for the clients to decide if and when they want to talk about their problems. Thus, when a client wants to see a counselor to talk about his or her problems, the client is encouraged to come to the counseling office. However, when the client does not want to see counselor, he or she does not have to. Instead, the counselors work with their parents and tutors in devising strategies to support and facilitate the client's recovery, thus providing indirect help.

A note should be made here about how the issue of confidentiality is dealt with as far as these clients are concerned. The concept of "group confidentiality" applies in many care-, support-, and treatment-provision situations in Japan. This concept is very similar to the privacy policy in hospitals, in which the privacy of the client is protected within the team of experts dealing with that client's needs, such as doctors, nurses, and medical administrators. When applied to the counseling situation (e.g., the clients in the third group), it means that pertinent information about the client is shared among psychotherapist, doctors, teachers, and even parents who may be directly involved in providing the necessary care for that client. Wada [39] described how, in Japan, the concept of group confidentiality was first introduced in courses for psychotherapists working in schools about ten years ago. This concept, and its associated practice, is now more widely used in counseling situations.

\section{CASE STUDIES}

This section describes three case studies from the first author's university counseling office. The counseling office is located on a campus for first-year students who are studying in medical sciences and related fields. Thus, the office mainly provides counseling for these first-year students who are required to stay in the university's student accommodation for one year.

As the students are in their first year of study, they usually encounter a host of new problems relating to various areas like the management of the demands of their studies, development of new personal relationships, and selection of 
group activities. In addition, this is the first time that most of the students live away from home and their parents, and some students experience difficulties in various facets of developing independence.

Furthermore, only a small proportion of the students actually select this medical department because of a personal desire to work in a medical institution in the future. The majority of students end up in this department simply as a consequence of following their parents' advice; many students in this department have one or both parents who are doctors. Some students choose this department just because their assessment scores in high school were relatively good, as entering medical departments usually require high scores in high school. These motivational issues also appear to contribute to mental health problems among students in this department.

Life at the university's student accommodation also appears to contribute directly to mental health problems. At the accommodation, four students usually share one room. This causes considerable stress among the students. In the shared room, it is very difficult for students to maintain their privacy in the same way they have been used to at home (where most students have their own room). The students also need to act as a group while residing at the accommodation. In Japan, students who act independently are often criticized by other students, so it is necessary to constantly be attentive to their room mates and to comply with what they want. This is particularly the case for most female students. Thus, it is not surprising that life at the student accommodation causes the most severe forms of stress among female students.

In Japanese culture, sensitivity to the subtle and nonverbally conveyed needs and predispositions of other people is expected from childhood, and the development of this sensitivity and the ability to respond appropriately is considered as an important aspect of maturity [40]. There are many dimensions to these complex societal customs that each individual is expected to learn to be attuned and responsive. Doi [41], for example, discussed the Japanese concept of "amae" which pertains to people behaving in a manner which is implicitly expectant of favors from other people, and noted both the positive and negative connotations of its practice. While it is outside the scope of this paper to describe these complex societal customs in detail, it is important to note that they significantly impact on the ways in which individuals think and behave in social situations. For young people who are leaving home for the first time, these complexities can present as additional sources of anxiety and psychological stress, which in turn can undermine confidence and identity development.

In order to support student life at the accommodation, tutors are appointed to help the students. One tutor usually takes charge of the four students sharing a room. The tutor often organizes dining parties to facilitate cohesion, provides tutoring in subjects that the students are taking, and discusses any problems that arise. They also provide basic mental health support. Along with these tutors, two other counselors provide mental health support for the students at the accommodation. Although students usually come to the counseling office of their own volition, some students make an appointment with the counselors following advice and encouragement from their tutor.

The three brief case studies from the first author's university counseling office are described below.

\section{Case 1}

Case 1 is of a male client who was classified into the first group. His problem concerned his personal relationship with one of his room mates. As his complaint was clear, the solution focused-approach was used in helping him resolve his problem.

The client explained that his room mate often criticized people and also often ignored him. Therefore he ceased to speak with that room mate. The interview also revealed that the client had a strong belief that people should not criticize other people. At the same time, he felt guilty because he could not accept his room mate for who he was. So the counselor prepared and asked one future-oriented question: "What kind of relationship do you want to build with your room mate before you leave the student accommodation?" To this question, the client answered that he would like to develop a relationship in which they had mutual respect for each other and would like to meet again even after they leave the accommodation. Then, with the counselor's encouragement, the client discussed how he could develop such a relationship with the room mate. As a first step, he decided to attempt to speak with his room mate whenever he met him in the dining room.

After a short time, the client returned to the counseling office and reported that his relationship with his room mate had improved. He had talked with his room mate, during which they realized that they had misunderstood each other. For example, the client found out that he unintentionally appeared as being cold towards his room mate, and the room mate in turn misinterpreted this as meaning the client disliked him.

After the counseling sessions, the client's mental health dramatically improved. Both the client and his room mate left the accommodation at the end of the academic year without any more problems, and they both successfully advanced to the second year of their courses.

\section{Case 2}

Case 2 is of a male client who was classified into the second group. He did not want to do anything and he was wondering if he should quit university. It seemed that he also suffered from an identity crisis, and from student apathy. Therefore, the counselor first talked with the client about the mental suffering he felt in relation to his university life and his past life.

During the psychoanalytic therapy sessions, the client told the counselor why he once dreamed of becoming a doctor. Furthermore, he explained that he was shocked and subsequently lost his motivation after he entered university and found other students to be so poorly motivated. He also told the counselor that he wanted a stable life but at the same time craved to live an exciting life. The psychoanalytic sessions revealed that the client had goals but suffered from a perception of a huge gap that seemed impossible to bridge between his dreams and reality. 
After the psychoanalytic therapy sessions, the futureoriented approach was applied. The counselor advised the client to reconsider what he wanted to do in the future. Although soon after that he ceased coming to the counseling office, he subsequently advanced to the second year of his studies and did not quit university. Through the counseling he received, it is likely that the client was able to return to the "starting line", considering his future again and confronting the challenges that were embodied in the gap he perceived between reality and his dreams.

\section{Case 3}

Case 3 is of a female client who was classified into the third group. Instead of the client, her tutor came to see the counselor to seek help for her. The client suffered from depression, various fears, and hallucination, and was diagnosed with schizophrenia. Therefore, a support network was established between the counselors in the counseling office, the tutor, and the client's mother. It was decided that mental health support for this client would be provided in conjunction with drug treatment provided through a medical institution.

The mental health support for this client was provided with the help of her tutor and her mother. During the summer holiday, when the counseling office was closed, arrangements were made for counselors from other universities to continue providing counseling sessions for the client. The counseling office also introduced a number of appropriate medical institutions to her mother so that the client could be provided the necessary medical treatment for her schizophrenic symptoms.

During her counseling sessions, the client revealed that her examination scores in high school were quite good and she was proud of herself and her achievements. She once dreamed of becoming a doctor. However, she failed to keep up with the demands of the medical classes at university, after which she gave up her dream of becoming a doctor and transferred to the nursing school in the same department. The high assessment scores she had managed to obtain in the nursing school probably helped her to maintain a reasonably good level of self-esteem. However, her failure in pursuing her dream of becoming a doctor probably led to an identity crisis and to feelings of depression, and significantly contributed to the onset of her schizophrenia. The support provided by the counseling office enabled her mother to remain strong and stable in her own mental state, so that she could listen to the client in a positive and supportive manner. Through the counseling sessions, the client also showed improvements in her mental state, and she ceased to suffer from strong fears and hallucinations.

\section{DISCUSSION}

This paper described key facets of the mental health support services provided by the university counseling office where the first author works. A significant proportion of the mental health problems experienced by Japanese university students appear to be caused by, or closely related to, identity crisis. Although the new life experiences that students encounter at university are exciting for most, students also confront a variety of challenging problems in personal relationships and their studies, as well as in having to make judgments and decisions on their own. In Japan, high school students rarely have opportunities to make important decisions by themselves. Therefore, the often sudden and stressful experiences requiring independent problem solving and decision making that Japanese students encounter at university prove valuable as facilitative steps toward their identity development. According to Erikson, the notion of "personal identity" includes career aspirations, values, romantic preferences, and political, religious and other beliefs that identify the individual as someone in particular and distinct from other people [42, 43]. Without opportunities for what Marcia referred to as "exploration" $[25,26]$ - which, in the case of Japanese students, is what the university experiences and challenges present - it is difficult to identify and sort through alternatives, to examine and question opinions and beliefs, and to deal with and resolve uncertainties so as to establish that sense of who one really is as distinct from other people.

However, even though the experiences and challenges that Japanese students encounter at university can be beneficial towards the development of their personal identity, the same experiences and challenges can cause considerable mental tribulations and stress, and some students are simply not able to deal with these on their own. They may experience what Erikson termed as "identity confusion" [44], a state of "inability to develop a workable set of ideals on which to base an adult identity" [45]. In less severe forms, such a state could simply manifest in not knowing what discipline to major in at college, or being uncertain whether one is truly willing to follow one's parents' footsteps as far as a career choice is concerned. In more serious cases, however, it could cause what Marcia referred to as "identity diffusion" which is characterized by being generally apathetic and disinterested, and could lead to maladaptive outcomes including academic failure, emotional distance from significant others, and deterioration of interpersonal skills [46]. In the first author's university counseling office, many of the students who are placed in the first category appear to be experiencing a less severe form of identity confusion, while many of those placed in the second and third categories - which include those suffering from student apathy - appear to be experiencing more severe symptoms.

Although in all cultures all adolescents and young adults have to contend with various facets and degrees of severity of identity crisis, the unique familial, educational, and societal situations in Japan are likely contributors to the unique ways in which identity crisis manifests in and impacts on the lives of students in Japanese universities. As noted earlier, there is a high incidence of student apathy among university students in Japan [3, 4], and the majority of mental health problems that students encounter and require help in resolving appear to be related to identity development issues. The unique challenges that these present to university mental health services, combined with limited resources (a problem experienced by most university student services worldwide), require the development of some unique approaches to the development of support for students.

The present authors consider the approach described in this paper as being appropriate in the Japanese setting. Although the counseling techniques used are drawn from existing techniques such as psychoanalysis and SFBT, the ways in which they have been adapted to address specific mental health challenges common to Japanese students are unique. As such, the approach described could serve as a helpful model in the development of similar mental health services for students in other universities in Japan. In addition, the described approach used in the first author's counseling office could contribute towards the promotion of intercultural comparisons and learning about 
commonalities and differences regarding university student experiences, the mental health problems they face, and the support services they are provided.

In the counseling strategy described in this paper, effective use is made of the solution-focused approach in helping students with both milder and more severe mental health problems. The solution-focused approach is used in guiding students not only to envision what they would consider to be a "preferable future" but also in formulating realistic and incremental steps they could take in attempting to redirect themselves towards that version of the future. Thus, the approach facilitates in students the development of greater selfknowledge (i.e., as far as their preferences are concerned), and a sense of how the present might connect with their "anticipated future". According to Erikson [44], both self-knowledge and the development of a sense of "a present with an anticipated future" are important in overcoming identity confusion and in promoting identity synthesis. The problem solving that is demanded of the solution-focused approach is also facilitative of what Marcia termed as "exploration", which is necessary in determining important life choices towards "identity achievement" [24].

However, in more serious cases of student mental health problems, the solution-focused approach alone is deemed insufficient: counselors in the first author's university also use the more traditional psychoanalytic approach to help students identify and understand the root causes in the past of problems they are currently experiencing. Without such understanding of the past, it is difficult to comprehend serious issues that are manifesting as problems in the present: many students, for example, who lack such understanding just keep repeating the same mistakes over and over, and progressively deteriorate in their mental health as a result of the subsequent repeated mental anguish. The importance of coming to terms with the past is central to Erikson's concept of "identity synthesis", which he viewed as "a reworking of childhood and contemporaneous identifications into a larger self-determined set of self-identified ideals" [45, 47].

The model of student mental health support provided at the first author's university also makes effective use of tutors and other people who can be considered as "significant others" to the student clients (e.g., their parents). Tutors, for example, not only advise and encourage students to seek counseling help when they show signs of mental distress, but also initiate the provision of counseling support when students cannot do that for themselves. Furthermore, tutors help counselors in the construction of support networks for students suffering from more severe forms of mental health problems. Thus, the mental health support provided to students is situated within the context of their "wider community" rather than just in the counseling offices, making that support an integral part of the students' day-to-day environment.

The appropriateness of this approach can be better appreciated when one considers tendencies in some societies - including the Japanese society - towards "interdependence" [48]. Interdependence, in contrast to independence, places greater emphasis on the relationships of individuals to each other, making it important to attend to others, to try to fit in, and to seek to establish and maintain harmonious relationships when possible [48]. Counseling strategies need to consider such tendencies in people and the corresponding environmental expectations and requirements in order to equip the client with realistic and environmentally valid means of overcoming the problems they are experiencing.

Although an eclectic approach to the provision of mental health support may not be unusual in the US and many other Western countries, it is less common in Japan. The tendency is for psychotherapists to keep to the specific methods and techniques of their particular discipline (e.g., psychoanalysis, behavior therapy, cognitive therapy). However, in most university settings, flexibility is clearly necessary, not only because of resource constraints but also the different kinds of desired outcomes in relation to the mental health issues that students present with. By describing how the eclectic approach has been put to effective use in one university counseling setting in Japan, the present authors hope that mental health professionals facing similar challenges could obtain some useful ideas and encouragement to adopt alternative techniques in considering the specific needs of their client groups.

\section{CONCLUSION}

The provision of support to students with mental health problems in the first author's university is by no means exemplary: counselors and others who contribute to the services provided are constantly looking for ways to improve this so that it may better meet the needs of student clients. The approach is also only one of many used in Japanese universities, so it cannot be taken as being representative. The authors chose to describe the approach here in order to illustrate one particular way for dealing with what appears to be a unique set of mental health problems relating to identity development prevalent among Japanese university students. The approach appears effective in helping many students suffering from apathy and other manifestations of identity crisis to regain their mental well-being. As noted earlier, the authors believe that sharing of student support practices like these not only contribute to professional development of university personnel, but also towards the cumulative enhancement of student support services and to intercultural learning and understanding.

\section{ACKNOWLEDGEMENT}

We appreciate the thoughtful contributions of Dr. Masashi Abe (National Research Institute for Cultural Properties, Tokyo) in the preparation of this paper.

\section{REFERENCES}

[1] Manalo E, Koyasu M, Hashimoto K, Miyauchi T. Factors that impact on the academic motivation of Japanese university students in Japan and in New Zealand. Psychologia 2006; 49: 114-31.

[2] Nakajima J. Suchudento apashii no yukue: Daigaku seishin eisei kenkyukai no 'Kyu Taigaku, Ryuunen Gakusei ni Kansuru Chosa' kara [Situations of apathy stricken students: Investigation of students who were temporarily absent, expelled or not promoted conducted by the Association of University Mental Hygiene]. Daigaku to Gakusei [Universities and Students] 1995; 357: 11-6.

[3] Shimoyama H. A study on the subclassification of moratorium of university students: In relation to the identity development. Jpn J Educ Psychol 1992; 40: 121-9.

[4] Shimoyama H. A review of studies on student apathy. Jpn J Educ Psychol 1996; 44: 350-63.

[5] Tetsushima K. A study on apathy tendency of university students: an analysis of some relevant factors. Jpn J Educ Psychol 1993; 41: 200-8. 
[6] Walters PA Jr. Student apathy. In: Blaine B Jr, McArtur CC, Eds. Emotional problems of the student. New York: Appleton-CenturyCrofts 1961; pp. 106-20.

[7] Mizutani Y, Kurato Y. Review of learned helplessness theory in Japan: The relationship between a causal attributional style and apathy instead of depression. Osakaichiritsu Daigaku Seikatsukagakubu Kiyou [Bulletin of the Faculty of Human Life Sciences, Osaka City University] 1994; 42: 99-106.

[8] Gason PA, Gauley K, Eds. College psychotherapy. New York: The Guilford Press 1989

[9] Aoki K. Suchudento apasii no shinriryouhou: Inisiesyon zushiki wo koete [Psychological therapy for student apathy]. Kyouto Daigaku Gakuseikonwasitsu Kiyou [Bulletin of the Mental Health Support Center, Kyoto University] 1988; 18: 1-52.

[10] Ono T. Suchudento apasii no naiteki sekai [Internal world of student apathy]. Jpn J Psychother 1987; 13: 375-83.

[11] Tuchikawa T. Students apathy and the life rhythm. Jpn J Educ Psychol 1985; 33: 771-3.

[12] Yamada K. Apasii to husei [Apathy and paternal relationship]. Jpn J Psychother 1984; 10: 149-54.

[13] Yamada K. Suchudento apasii no kihonbyouri: Tyouki juudanteki kansatsu no rokujyuurei kara [Basic pathology of student apathy: Sixty cases from longitudinal observations]. In: Hirai T, Ed. Gendaijin no sinri to byouri [Psychology and pathology of modern people]. Tokyo: Saiensu Pures 1987; pp. 355-73.

[14] Yamada K. Kyoukairei no syuuhen: Sabukurinikaruna mondaiseikakugun [Around the borderline cases: Problematic characteristics just before clinical treatment]. Jpn J Psychother 1989; 15: 350-60.

[15] Yamada K. Kazokukankei no nakadeno sutyudento apasii [Students' apathy from the pathology of family relations]. Kokorono Kenkou [Mental Health] 1990; 5: 2-16.

[16] Mouri KA, Sagami T. A research about the relation between apathy tendency in college students and their parents' attitudes. Bull Aichi Univ Fac Educ 2008; 55: 47-53.

[17] Holland JL, Gottofredson DC, Power PG. Some diagnostic scales for research in decision making and personality: Identity, information and barriers. J Pers Soc Psychol 1980; 39: 1191-200.

[18] Holland JL, Holland JE. Vocational indecision: More evidence and speculation. J Couns Psychol 1977; 24: 404-14.

[19] Osipow SH, Carney CG, Barak A. A scale of educational-vocational undecidedness: A typological approach. J Vocat Behav 1976; 9: 23343.

[20] Shimoyama H. A study on the relation between state of personality development and career decision-making of high school students. Jpn J Educ Psychol 1983; 31: 56-61.

[21] Shimoyama H. A Longitudinal study on the career decision-making process of a high school. Jpn J Educ Psychol 1984; 32: 206-11

[22] Uruta U, Takano A. Construction of a student counseling system: collaboration between psychology and college education. Jpn J Educ Psychol 2003; 51: 205-17.

[23] Sonaka T, Aoki K. Tengakubu/tengakka no jittai: Sonogono gakuseiseikatsu [Field survey involving students' change of department and discipline at university: Campus life after making the change]. Kyouto Daigaku Gakuseikonwasitu Kiyou [Bulletin of the Mental Health Support Center, Kyoto University] 1982; 12:36-54.

[24] Marcia JE. Development and validation of ego identity status. J Pers Soc Psychol 1966; 3: 551-8.

[25] Marcia JE. Identity and psychotherapy. In: Archer SL, Ed. Interventions for adolescent identity development. Thousand Oaks, CA: Sage 1994; pp. 29-46.
[26] Marcia JE. The empirical study of ego identity. In: Bosma HA, Graafsma TLG, Grotevant HD, de Levita DJ, Eds. Identity and development: An interdisciplinary approach. Thousand Oaks, CA: Sage 1995; pp. 67-80.

[27] Grotevant HD. Toward a process model of identity formation. J Adolesc Res 1987; 2: 203-22.

[28] Marcia JE. Identity in adolescence. In: Adelson J, Ed. Handbook of adolescent psychology. New York: Wiley 1980; pp. 159-87.

[29] Marcia JE. Common processes underlying ego identity, cognitive/moral development, and individuation. In: Lapsley DK, Power FC, Eds. Self, ego, and identity: Integrative approaches. New York: Springer-Verlag 1988; pp. 211-66.

[30] Sexton TL, Weeks GR, Robbins MS, Eds. Handbook of family therapy: The science and practice of working with families and couples. New York: Brunner-Routledge 2003.

[31] de Shazer S, Berg IK, Lipchik E, et al. Brief therapy: Focused solution development. Fam Process 25; 1986: 207-21.

[32] Harada U. Daigakusei no syouraimokuhyou wo taisyoutoshita kaiketusikou apurouchi niyoru ninchihenyouu ni kansuru jikkennteki kenkyuu [Experimental study about cognitive change in university students following the use of the solution-focused counseling approach]. Jpn J Brief Psychother 2002; 11: 68-76.

[33] Kurosawa S. Shidouenjyo ni yakudatsu sukurukaunseringu wakubukku [Workbook for supporting school counseling]. Tokyo: Kaneko Syobou 2002

[34] Chiba H. Behavior therapeutic understanding of a solution-focused approach: The significance of positive-orientation and future-orientation in counseling. Bull Coll Sociol Shukutoku Univ 1998; 32: 51-67.

[35] Motomura M. A study on the feature of solution focused approach by comparing with traditional social work methods: A discussion regarding on sustaining procedure. Bull Fac Law Lett Univ Ryukyuus 2008; 21:143-64.

[36] Fukuda S. Cooperation of psychiatric care and student counseling. Jpn J Psychother 2007; 33: 565-70.

[37] Shimoyama H. Gakkou/katei/chiiki wo tougousuru sapouto nettowaku: Raifusaikuru wo jikutoshite [Support network integrating school, family, and local community: Centering around the life cycle]. Mindix 2001; 7(4): 8-13.

[38] Engel GL. The need for a new medical model: A challenge for biomedicine. Science 1977; 196(4286): 129-36.

[39] Wada Y. The consideration of counseling training in school counseling: This is examined through the passage of ten years and "healing training" by using collage technique is proposed. Bulletin of Mimasaka University and Mimasaka Junior College 2008; 53: 97-105.

[40] Tamura T. What it means to achieve maturity: Cultural comparison of the concept of individuality. Jidoushinri [Mentality of Children] 1997; 51(4): 330-5.

[41] Doi T. Amae no kouzou [The anatomy of dependence]. Tokyo: Koubundou 2001

[42] Erikson EH. Dimensions of a new identity. New York: Norton 1974.

[43] Erikson EH. Identity and the life cycle. New York: Norton 1980.

[44] Erikson EH. Identity: Youth and crisis. New York: Norton 1968.

[45] Schwartz SJ. The evolution of Eriksonian and neo-Eriksonian identity theory and research: A review and integration. Identity 2001; 1: 7-58.

[46] Marcia JE. Identity in adolescence. In: Adelson J, Ed. Handbook of adolescent psychology. New York: Wiley 1980; pp. 159-87.

[47] Erikson EH. Childhood and society. New York: Norton 1950

[48] Markus HR, Kitayama S. Culture and the self: Implications for cognition, emotion, and motivation. Psychol Rev1991; 98: 224-53. 